\title{
Remarkable Photocatalytic Behavior of WO3 /MoS2 Heterostructure: Insights From a Combined Experimental and Theoretical Investigations
}

\author{
Sulakshana Shenoy \\ National Institute of Technology Karnataka \\ Kishore Sridharan \\ University of Calicut \\ Kartick Tarafder ( $\nabla$ karticktarafder@gmail.com ) \\ National Institute of Technology Karnataka
}

\section{Research Article}

Keywords: photocatalytic, heterostructure, experimental, Z-scheme

Posted Date: August 24th, 2021

DOI: https://doi.org/10.21203/rs.3.rs-826094/v1

License: (c) (i) This work is licensed under a Creative Commons Attribution 4.0 International License.

Read Full License 


\title{
Remarkable photocatalytic behavior of $\mathrm{WO}_{3} / \mathrm{MoS}_{2}$ heterostructure: Insights from a combined experimental and theoretical investigations.
}

\author{
Sulakshana Shenoy ${ }^{1}$, Kishore Sridharan $^{2}$, and Kartick Tarafder ${ }^{1, *}$ \\ ${ }^{1}$ Department of Physics, National Institute of Technology Karnataka, P.O. Srinivasnagar, Surathkal, Mangalore \\ 575025, India \\ ${ }^{2}$ Department of Nanoscience and Technology, School of Chemical and Physical Sciences, University of Calicut, \\ Kerala 673635, India \\ *karticktarafder@gmail.com
}

\begin{abstract}
The Z-scheme heterogeneous photocatalytic system simulates the natural photosynthesis process and can overcome the shortcomings of the single-component photocatalyst, and possess many merits, including increased light-harvesting, spatially separated reductive and oxidative sites, and well-preserved strong redox ability, which benefits the photocatalytic performance. Here we report the fabrication of a novel $\mathrm{WO}_{3} / \mathrm{MoS}_{2}$ heterojunction via the hydrothermal method, with the structure, electronic and photocatalytic properties analyzed by means of experimental and theoretical methods. Photocatalytic studies have been conducted on methylene blue dye under visible light in the presence of $\mathrm{WO}_{3} / \mathrm{MoS}_{2}$ heterostructure, and the degradation rate was as high as $90 \%$ within 60 min of light irradiation. A detailed theoretical study of this system shows that an internal electric field at the interface of the heterojunction was formed directed from $\mathrm{MoS}_{2}$ to $\mathrm{WO}_{3}$, which helps to separate the photogenerated electron-hole pairs efficiently through a direct Z-scheme charge transfer process. This work also demonstrated the significant potential of $\mathrm{WO}_{3} / \mathrm{MoS}_{2}$ heterostructure towards hydrogen evolution reaction.
\end{abstract}

\section{Introduction}

The production of clean energy from renewable energy sources in an efficient and cost-effective manner is one of the biggest challenges of this century. Towards this end, hydrogen has been extensively investigated by several groups for the past few decades as an alternative to the diminishing fossil fuel ${ }^{1}$. Electrocatalytic or photocatalytic water splitting with zero emission of $\mathrm{CO}_{2}$ serves as the major technology to produce hydrogen ${ }^{2}$. Therefore, designing efficient semiconductor photocatalysts for photo/electrocatalytic hydrogen evolution has recently drawn great research attention. In general, the hydrogen adsorption free energy $\left(\Delta \mathrm{G}_{H}\right)$ at the surface of a catalyst determines the efficiency of hydrogen desorption and adsorption ${ }^{3}$. By the Sabatier mechanism, the interactions between reactants and catalysts should neither be too strong nor too weak, for the reaction to proceed efficiently. Thus catalyst with $\Delta \mathrm{G}_{H}$ close to zero shows excellent performance for hydrogen evolution reaction (HER $)^{4,5}$. Although metals like Pt, Re, Rh, and Ir exhibit excellent catalytic activity for hydrogen generation because of their optimal hydrogen adsorption free energies, but their expensiveness and scarcity greatly inhibit large-scale industrial applications ${ }^{6,7}$. Consequently, it is desirable to explore the possibility of designing materials with a reduced production/maintenance cost and having excellent photo/electro-catalytic activity for the large-scale hydrogen generation.

Recently, a class of quasi two dimensional (Q2D) materials with interesting electronic and optical properties, has become very important in the field of nanomaterials, and it has also shown its great potential in catalytic applications. Transition metal dichalcogenides, in particular $\mathrm{MoS}_{2}, \mathrm{WS}_{2}, \mathrm{TcS}_{2}$, and $\mathrm{PtS}_{2}$ have recently been investigated as active materials for hydrogen evolution reaction $^{8-11}$. On the other hand transition metal oxides (TMOs) can also be used as effective materials for the catalytic process. It has been observed that by introducing oxygen vacancies into the system, the catalytic activity of TMOs can be significantly improved ${ }^{12-14}$. These vacancies provide active sites to the catalysts, increase their conductivity, and raise their electrocatalytic performance remarkably. Tungsten trioxide $\left(\mathrm{WO}_{3}\right)$ is one such compound that has recently been given added attention owing to its non-toxicity and unique optical behavior ${ }^{15-17}$. Furthermore, it has many other exciting merits such as inexpensiveness, ease of synthesis, good stability both under acidic and basic conditions, excellent electron transport ability, photo-corrosion resistance, etc. ${ }^{18,19}$. However, the photocatalytic activity of pure $\mathrm{WO}_{3}$ is limited because of its narrow light absorption range and rapid recombination of photogenerated electron-hole pairs in the system ${ }^{20}$. Therefore, functional material such as a combination of metal oxide and metal dichalcogenides heterostructure may provide an alternate route for 
designing highly efficient electro/photocatalytic materials. Also, it is a well-known fact that, compared to a single photocatalyst, heterojunction photocatalysts composed of two different semiconductors have the advantage of speeding up the separation of photogenerated charges. Many such heterostructures follow the Z-scheme reaction process, in which reduction and oxidation reactions are carried out at two different semiconductors, which effectively escalates the photocatalytic process ${ }^{21,22}$. The Z-scheme photocatalytic process involves two-step photoexcitation. In the first step, the electrons in the valence band of semiconductor II (SC-II) are excited to its conduction band by absorbing comparatively lower wavelength radiation. These photoexcited electrons are then channelized towards the other semiconductor part (SC-I) through medium receptors. In the next step when electrons are excited from the valence band of SC-I to its conduction band by absorbing relatively higher wavelength radiation, the channelized electrons from the conduction band of SC-II then recombine with the photogenerated holes in the SC-1 valence band. Therefore, effectively the electron-hole pairs are separated out and are left in the conduction band of SC-I and the valence band of SC-II respectively. The photogenerated holes on the valence band of SC-II have strong oxidation ability and can easily oxidize water and/or organic pollutants, meanwhile, the electrons on the conduction band of SC-I have strong reduction ability and can be utilized to generate hydrogen or to reduce $\mathrm{CO}_{2}$. Therefore, the construction of the Z-scheme photocatalytic system not only features the spatial separation of photogenerated charge carriers but also inhibits electron-hole recombination. The scheme is also beneficial for the thermodynamic redox reactions, as in normal hydrogen electrode scale, conduction band and valence band potentials in the heterojunction appear to be more negative and more positive respectively compare to the band potentials of individual semiconductor photocatalyst. In this study, we have used $\mathrm{MoS}_{2}$ coupled with $\mathrm{WO}_{3}$ to make a novel heterostructure catalyst.

Attempts have already been made using similar heterojunctions for $\mathrm{H}_{2}$ production and photodegradation of organic pollutants. Higher catalytic performance has also been observed in many cases ${ }^{23-26}$, yet, up to now, a detailed microscopic understanding, as well as the route cause of higher photocatalytic activity in this heterostructure, is still lacking. In particular, the intrinsic relationships among the electronic structure and photocatalytic activity of $\mathrm{WO}_{3} / \mathrm{MoS}_{2}$ heterojunction are still not clear. For an efficient HER process, photocatalyst should possess critical values of few important parameters, such as suitable bandgap and reasonable positions of the conduction band minimum (CBM) and valence band maximum (VBM) with respect to the water redox potentials ${ }^{27,28}$. Herein, we carefully investigated the electronic structure, band edge alignment, and optical properties of the $\mathrm{WO}_{3} / \mathrm{MoS}_{2}$ heterostructure by adopting the hybrid density functional theory calculations. We put forward the optimum conditions that are important to accurately predict the adsorption energy for the individual and heterostructure catalytic surfaces on its HER activity. Besides, we have successfully fabricated the $\mathrm{WO}_{3} / \mathrm{MoS}_{2}$ composite by a hydrothermal process and investigated their photocatalytic activity. Visible light-driven photocatalytic degradation of methylene blue (MB) dye in the presence of pristine $\mathrm{WO}_{3}, \mathrm{MoS}_{2}$ and $\mathrm{WO}_{3} / \mathrm{MoS}_{2}$ composite photocatalyst was performed for this purpose. Our results indicate a remarkable enhancement in the rate of photodegradation of $\mathrm{MB}$ in presence of a heterojunction photocatalyst. Moreover, the mechanism of the improved photocatalytic activity of the composite was also studied in detail that could be useful for the understanding of the hydrogen evolution process.

\section{Results}

\subsubsection{Morphological, chemical and structural characterization}

The clear and intense XRD patterns of pristine $\mathrm{WO}_{3}, \mathrm{MoS}_{2}$ and $\mathrm{WO}_{3} / \mathrm{MoS}_{2}$ nanocomposite are represented in Fig.1. All the characteristic peaks of pristine $\mathrm{WO}_{3}$ can be indexed to hexagonal phase with lattice constants of $\mathrm{a}=\mathrm{b}=7.30 \AA$, $c=3.90 \AA$ as reported in literature (JCPDS card \# 33-1387) ${ }^{29}$. While the diffraction pattern of pristine $\mathrm{MoS}_{2}$ was well-matched with the hexagonal phase (JCPDS card \# 37-1492) ${ }^{30}$. On examining XRD patterns of $\mathrm{WO}_{3} / \mathrm{MoS}_{2}$ nanocomposite, the diffraction peaks of both $\mathrm{WO}_{3}$ and $\mathrm{MoS}_{2}$ can be detected and this confirmed that they were produced successfully. FESEM micrographs of $\mathrm{WO}_{3}$ obtained at two different magnifications are shown in Fig.2a and Fig.2b. The general description of the uniform distribution of $\mathrm{WO}_{3}$ particles in a massive form can be clearly seen in the low magnification FESEM micrograph showed in Fig.2a. The magnified FESEM micrograph shown in Fig. $2 \mathrm{~b}$ confirms the formation of two-dimensional $\mathrm{WO}_{3}$ nano blocks with widths of $0.8-1 \mu \mathrm{m}$ and thicknesses of $60-100 \mathrm{~nm}$. In the EDS spectrum shown in Fig.2c, except for the elements corresponding to $\mathrm{W}$ and $\mathrm{O}$, no $\mathrm{X}$-ray peaks of the elements indicate the purity of the synthesized $\mathrm{WO}_{3}$ nano blocks. On the other hand, Fig.2d and Fig.2e represent the FESEM micrographs of the $2 \mathrm{D} \mathrm{MoS}_{2}$ obtained by the hydrothermal method. FESEM analysis under both low and high magnifications showed that a two-dimensional sheet-like structure of $\mathrm{MoS}_{2}$ was formed, which agglomerated into particles with a diameter of $100-150 \mathrm{~nm}$. In the EDS spectrum shown in Fig.2f, except for those elements corresponding to Mo and S, no X-ray peaks of other elements indicate the purity of the $\mathrm{MoS}_{2}$ nanosheets. FESEM micrographs of $\mathrm{WO}_{3} / \mathrm{MoS}_{2}$ nanocomposite presented in Fig.2g and Fig.2h show the mixed morphology of $\mathrm{MoS}_{2}$ nanosheets embedded on $\mathrm{WO}_{3}$ nano blocks. Magnified FESEM micrograph in Fig.2h clearly depicts the presence of $\mathrm{MoS}_{2}$ nanosheets interconnected with $\mathrm{WO}_{3}$ nanoblocks. EDS spectrum of $\mathrm{WO}_{3} / \mathrm{MoS}_{2}$ nanocomposite shown in Fig.2i, reveals the presence of elemental peaks corresponding only to $\mathrm{W}, \mathrm{O}, \mathrm{Mo}$, and $\mathrm{S}$, confirming the formation of heterostructure and the purity of the sample. 


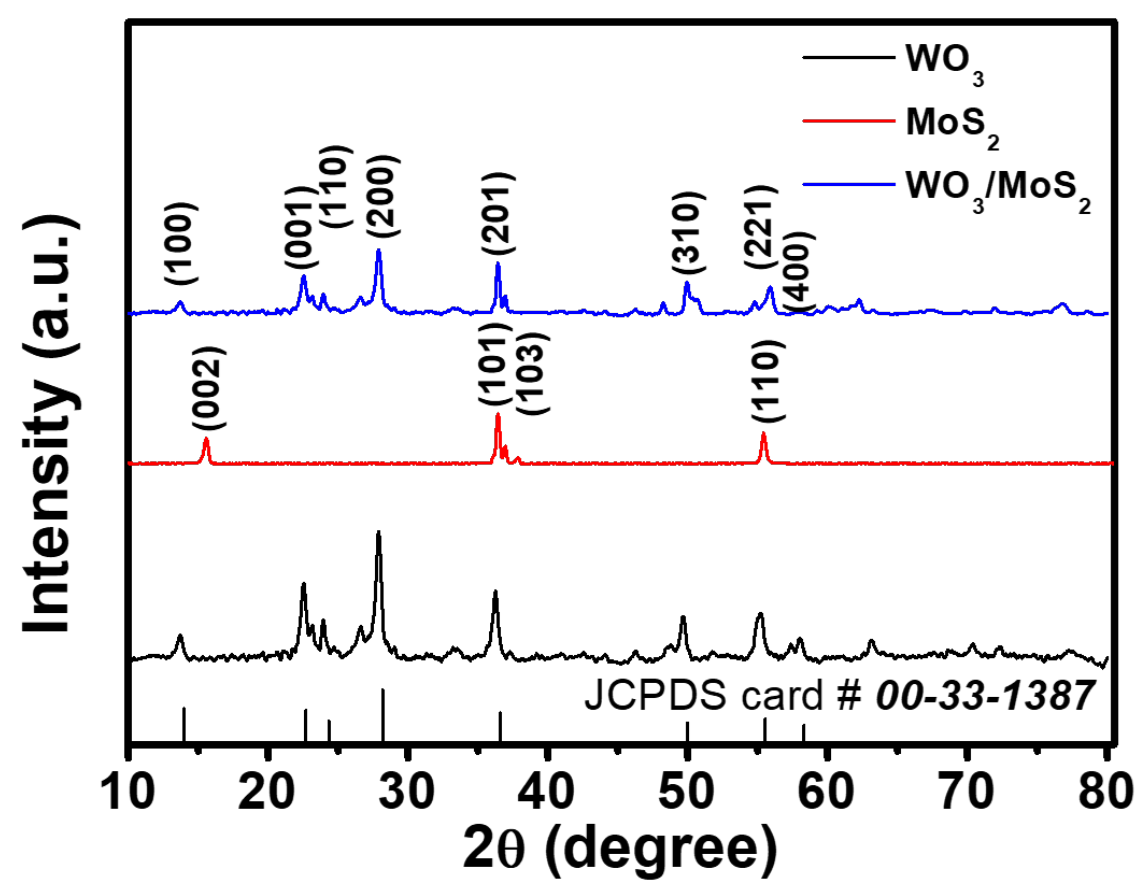

Figure 1. X-ray diffraction patterns of pristine $\mathrm{WO}_{3}, \mathrm{MoS}_{2}$ and $\mathrm{WO}_{3} / \mathrm{MoS}_{2}$ composite photocatalysts.

\subsubsection{Optical property(experimental)}

The UV-vis diffuse reflectance spectroscopy (DRS) was employed to study the optical properties of the as-synthesized samples and estimate their bandgap energy. DRS is related to the absorption coefficient by the Kubelka-Munk (K-M) function F(R) given by

$$
F(R)=\frac{(1-R)^{2}}{2 R}
$$

where reflectance $\mathrm{R}=\mathrm{R}_{\text {sample }} / \mathrm{R}_{\text {reference }}{ }^{31}$. MoS 2 physically appears as a black powder. Due to its relatively narrow bandgap, it has an absorption in the visible light region. The DRS in Fig.3a shows that the absorption edge of $\mathrm{MoS}_{2}$ is around $650 \mathrm{~nm}$. On the other hand, pristine $\mathrm{WO}_{3}$ shows an absorption edge at $440 \mathrm{~nm}$. Fig. $3 \mathrm{~b}$ showing the plot of $[\mathrm{F}(\mathrm{R}) \mathrm{h} v]^{1 / 2}$ versus $\mathrm{h} v$ was used for deducing the corresponding bandgap energy of the as-synthesized photocatalysts by extrapolating the linear portion of the graph to $[\mathrm{F}(\mathrm{R}) \mathrm{h} v]^{1 / 2}=0$. The DRS data in Fig.3a confirm that with $\mathrm{MoS}_{2}$ loading, the energy bandgap of $\mathrm{WO}_{3}$ decreases from $2.8 \mathrm{eV}$ to $2.4 \mathrm{eV}$, indicating the improved visible light absorption capability of $\mathrm{WO}_{3} / \mathrm{MoS}_{2}$ composite photocatalyst.

\subsubsection{Geometry, structure and stability}

Before analyzing the electronic properties of pristine $\mathrm{MoS}_{2}$ and $\mathrm{WO}_{3}$, full geometry relaxation of the atomic coordinates and lattice parameters are achieved. Both $\mathrm{WO}_{3}$ and $\mathrm{MoS}_{2}$ belong to hexagonal structure with $P 6 / \mathrm{mmm}$ and $P 6_{3} / \mathrm{mmc}$ space group respectively. The optimized lattice parameters and the bandgap of the relaxed monolayers calculated by using HSE06 functional are summarised in Table 1, which shows an excellent agreement with the reported experimental and theoretical values ${ }^{24,32}$. The optimized Mo-S bond length in $\mathrm{MoS}_{2}$ monolayer and W-O bond length in $\mathrm{WO}_{3}$ are found to be $2.408 \AA$ and $1.93 \AA$ A respectively. Fig.4a and Fig. 4 b show top views of monolayer $\mathrm{MoS}_{2}$ and monolayer $\mathrm{WO}_{3}$ with $3 \times 3$ lateral periodicity respectively. Fig.4c illustrates the geometric structure of $\mathrm{WO}_{3} / \mathrm{MoS}_{2}$ heterojunction where the lattice mismatch is less than $1.3 \%$. To further investigate the adsorption interaction between $\mathrm{WO}_{3}$ and $\mathrm{MoS}_{2}$ surface at the interface, the interfacial cohesive 

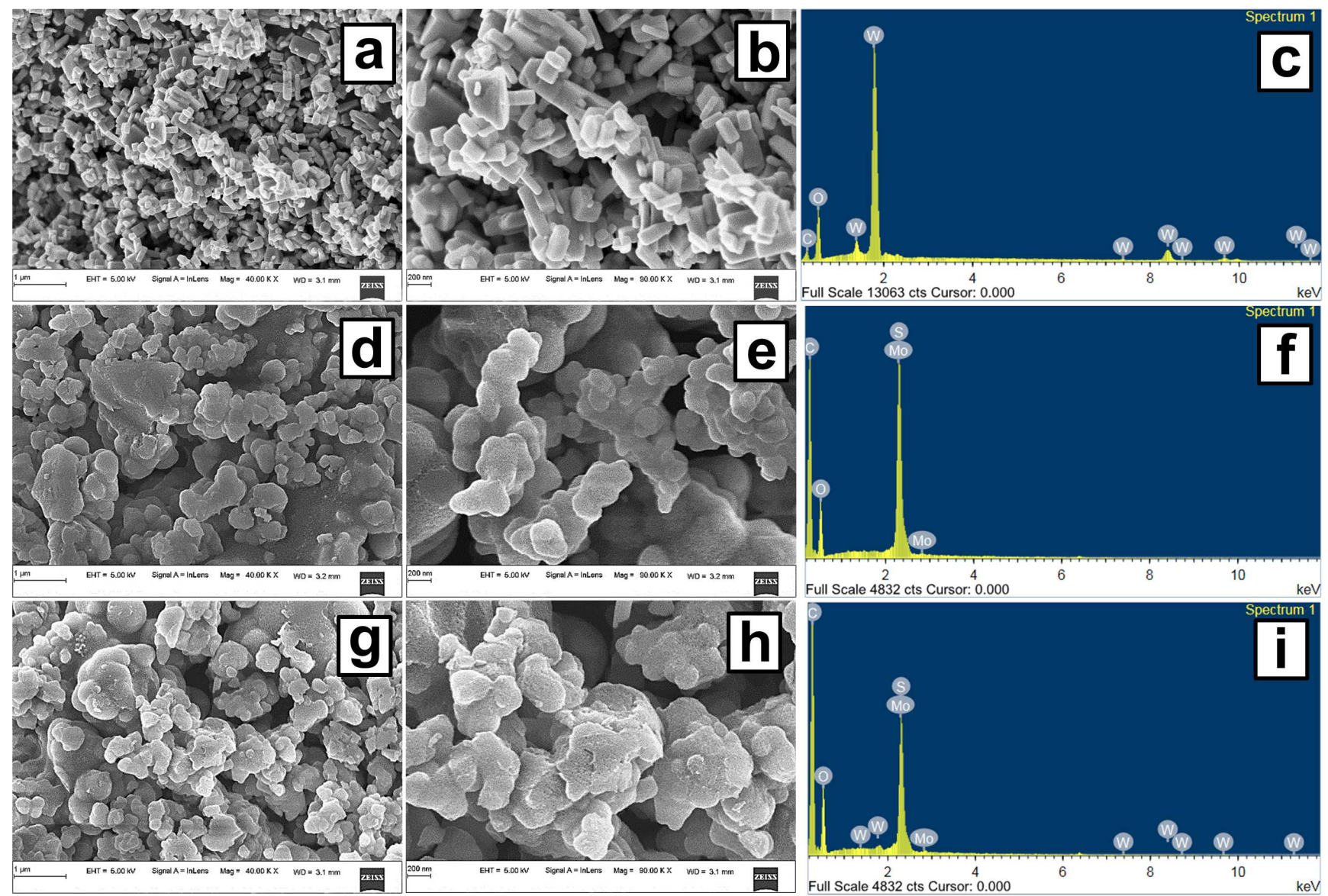

Figure 2. Morphological and chemical characterization of the as-synthesized $\mathrm{WO}_{3}, \mathrm{MoS}_{2}$ and $\mathrm{WO}_{3} / \mathrm{MoS}_{2}$ photocatalysts. FESEM micrographs under two different magnifications corresponding to (a, b) $\mathrm{WO}_{3}$, (d, e) $\mathrm{MoS}_{2}$ and $(\mathrm{g}, \mathrm{h}) \mathrm{WO}_{3} / \mathrm{MoS}_{2}$ photocatalysts. EDS spectrum corresponding to (c) $\mathrm{WO}_{3}$, (f) $\mathrm{MoS}_{2}$ and (i) $\mathrm{WO}_{3} / \mathrm{MoS}_{2}$ composite.

energy was obtained by using the following equation:

$$
E_{c o h}=E_{W O_{3} / M_{2}}-E_{W O_{3}}-E_{M o S_{2}}
$$

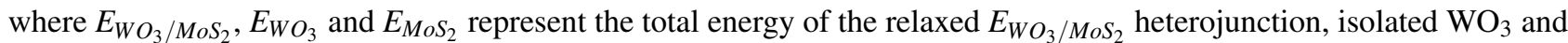
isolated $\mathrm{MoS}_{2}$ respectively. The calculated cohesive energy was $-0.81 \mathrm{eV}$ for the entire model interface. The negative cohesive energy indicated that the $\mathrm{WO}_{3} / \mathrm{MoS}_{2}$ composite could form a stable interface.

\subsubsection{Band structure and partial density of states}

To describe the interaction in the heterojunction more clearly, band structures and partial density of states (PDOS) for WO $\mathrm{W}_{3}$ $\mathrm{MoS}_{2}$ and $\mathrm{WO}_{3} / \mathrm{MoS}_{2}$ heterostructure are simulated based on HSE06 functional calculation and are illustrated in Fig.5a-Fig.5c.

Table 1. Optimized lattice parameters, calculated band gap energy, work functions and band edge positions of pristine $\mathrm{WO}_{3}$ and $\mathrm{MoS}_{2}$.

\begin{tabular}{|c|c|c|c|c|c|c|c|}
\hline \multirow[t]{2}{*}{ System } & \multicolumn{3}{|c|}{ Lattice parameter } & \multirow{2}{*}{$\begin{array}{c}\mathrm{E}_{g} \\
(\mathrm{eV})\end{array}$} & \multirow{2}{*}{$\begin{array}{c}\Phi \\
(\mathrm{eV})\end{array}$} & \multirow{2}{*}{$\begin{array}{l}\mathrm{E}_{V B} \\
(\mathrm{eV})\end{array}$} & \multirow{2}{*}{$\begin{array}{l}\mathrm{E}_{C B} \\
(\mathrm{eV})\end{array}$} \\
\hline & $\mathrm{a}$ & $\mathrm{b}$ & $\mathrm{c}$ & & & & \\
\hline $\mathrm{WO}_{3}$ & 7.298 & 7.298 & 3.899 & 3.0 & 6.13 & 3.59 & 0.59 \\
\hline $\mathrm{MoS}_{2}$ & 3.16 & 3.16 & 12.29 & 1.75 & 4.76 & 1.69 & -0.1 \\
\hline
\end{tabular}



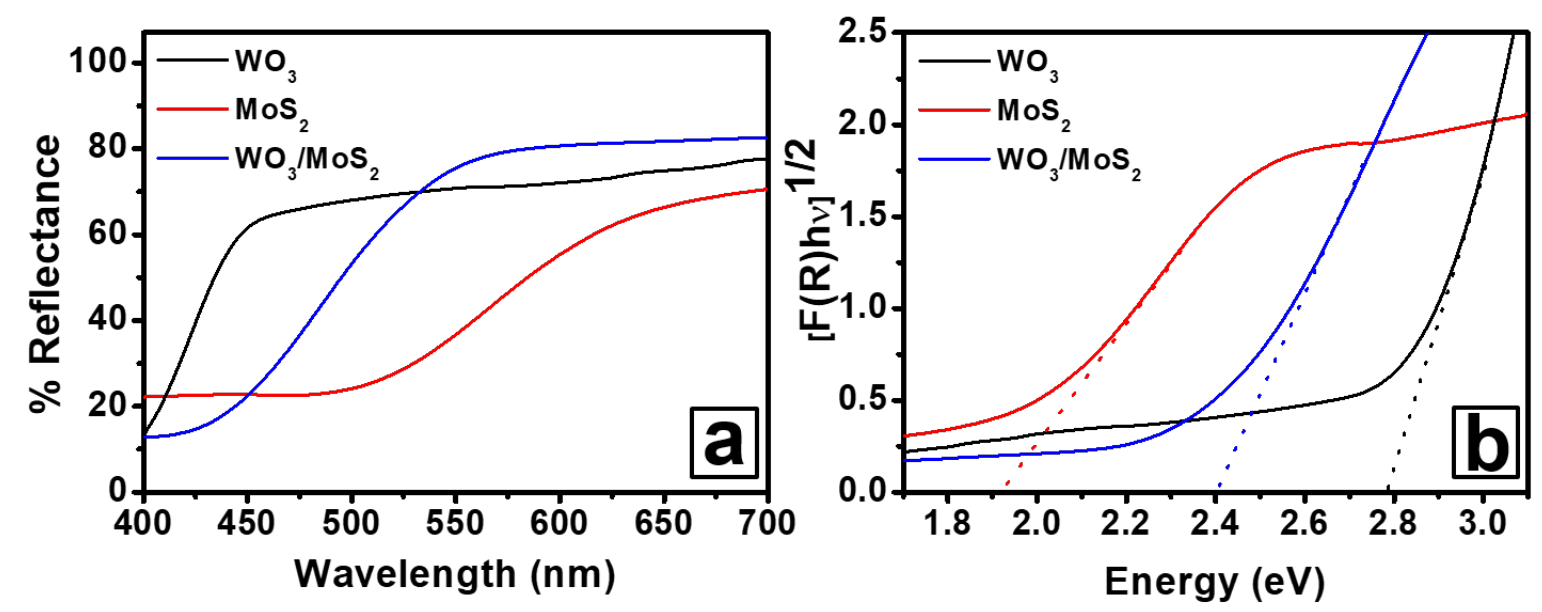

Figure 3. (a) UV-Vis diffuse reflectance spectra of the as-synthesized $\mathrm{WO}_{3}, \mathrm{MoS}_{2}$ and $\mathrm{WO}_{3} / \mathrm{MoS}_{2}$ composite photocatalysts and (b) the corresponding Tauc's plot $\left([\mathrm{F}(\mathrm{R}) \mathrm{h} v]^{1 / 2} v s \mathrm{~h} v\right)$. Extrapolated dashed lines touching the intercept on the $\mathrm{x}$-axis indicate the effective bandgap energy of the photocatalysts.

(a)

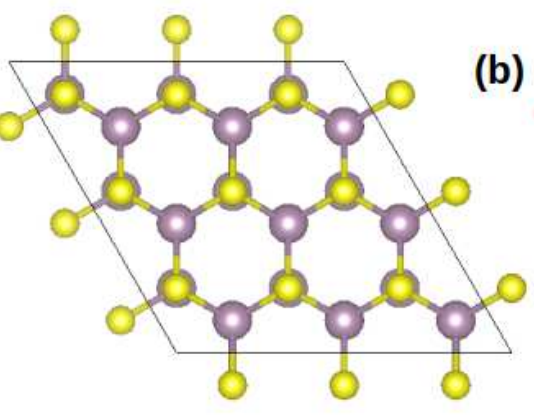

(b)

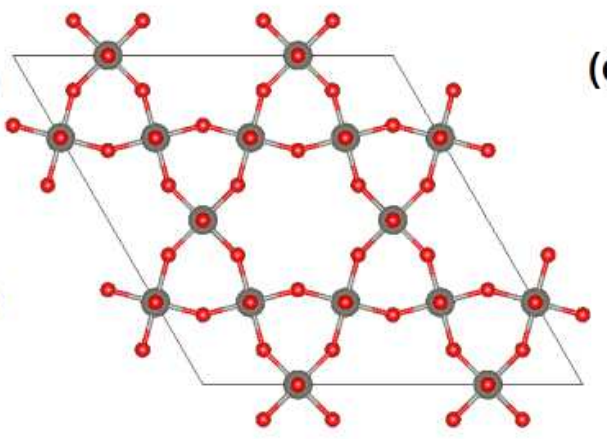

(c)

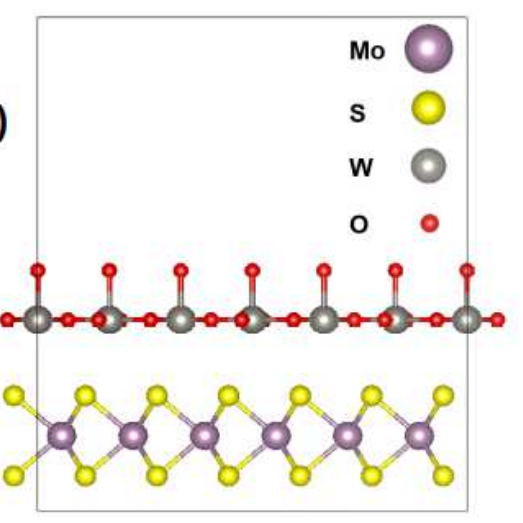

Figure 4. Optimized geometric structures of (a) $\mathrm{MoS}_{2}$, (b) $\mathrm{WO}_{3}$ and (c) $\mathrm{WO}_{3} / \mathrm{MoS}_{2}$ heterostructure.

Monolayer $\mathrm{MoS}_{2}$ has a direct bandgap $\left(\mathrm{E}_{g}\right)$ of $1.75 \mathrm{eV}$ where both the valence band maximum (VBM) and conduction band minimum $(\mathrm{CBM})$ is located at high symmetry point $\mathrm{K}$. The simulated bandgap of $\mathrm{WO}_{3}$ is also direct in nature with $\mathrm{E}_{g}=3.0 \mathrm{eV}$ at $\mathrm{K}$ point. Interestingly, the $\mathrm{WO}_{3} / \mathrm{MoS}_{2}$ heterostructure also posses a direct gap of $2.0 \mathrm{eV}$, with $\mathrm{VBM}$ and $\mathrm{CBM}$ at $\mathrm{K}$ point. Note that the direct bandgap estimated in the case of heterostructure makes it beneficial for easier transfer of electrons from the VBM 
to the CBM. To explore the distribution of electrons and charge carrier migration path at the interface of the heterostructure, the partial density of states of $\mathrm{WO}_{3}, \mathrm{MoS}_{2}$ and $\mathrm{WO}_{3} / \mathrm{MoS}_{2}$ heterostructure are plotted. Fig.5a illustrates that $\mathrm{VBM}$ of $\mathrm{WO}_{3}$ is constructed by $\mathrm{O}(\mathrm{p}$ ) orbitals, while its CBM is comprised of W (d) orbital. From Fig.5b it is clear that both VB and CB edges of $\mathrm{MoS}_{2}$ are almost equally occupied by Mo (d) and S (p) orbitals respectively. For the heterostructure (see Fig.5c), the VBM is dominated by the Mo (d) and S (p) orbitals, while the CBM is composed of W (d) and O (p) orbitals. Under visible light irradiation, the electrons in $\mathrm{MoS}_{2}$ can be easily transferred into $\mathrm{WO}_{3}$. Therefore, the introduction of $\mathrm{MoS}_{2}$ monolayer is expected to improve the visible light photocatalytic performance of $\mathrm{WO}_{3}$. This suggests that $\mathrm{MoS}_{2}$ acts as a visible light sensitizer in the heterostructure may help to successfully separate photogenerated electron-hole pairs via the interface charge transfer process.

\subsubsection{Optical property(theoretical)}

The optical absorption is another key parameter required to describe the photocatalytic performance of materials. The complex dielectric function $\left(\varepsilon=\varepsilon_{1}+\mathrm{i} \varepsilon_{2}\right)$, its real part $\left(\varepsilon_{1}\right)$ and imaginary part $\left(\varepsilon_{2}\right)$ are calculated by applying linear response theory after obtaining accurate ground-state electronic structure of the system. Subsequently, the absorption coefficient $\alpha(\omega)$ was estimated from the following relation,

$$
\alpha(\omega)=\sqrt{2} \omega \sqrt{\sqrt{\varepsilon_{1}^{2}(\omega)+\varepsilon_{2}^{2}(\omega)}-\varepsilon_{1}(\omega)}
$$

where $\omega$ represents the angular frequency ${ }^{32}$. To examine the effect of $\mathrm{WO}_{3} / \mathrm{MoS}_{2}$ combination on the photocatalytic efficiency, the optical absorption spectra of the pristine $\mathrm{WO}_{3}$, pristine $\mathrm{MoS}_{2}$ and $\mathrm{WO}_{3} / \mathrm{MoS}_{2}$ heterostructure are investigated by calculating the imaginary part of the complex dielectric function, as shown in Fig.6. In the visible light range $(2.0-3.1 \mathrm{eV})$, the optical absorption coefficient of the $\mathrm{WO}_{3} / \mathrm{MoS}_{2}$ heterostructure is significantly higher than that of individual $\mathrm{WO}_{3}$ and $\mathrm{MoS}_{2}$, implying a stronger light absorption ability of the hetero-structure in a wider absorption range. The redshift of the absorption edge in the heterostructure is attributed to the appearance of a new hybridized electronic state due to the formation of the heterostructure which allows the electron excitation between different components.

\subsubsection{Charge density difference}

The strong hybridization of state in $\mathrm{MoS}_{2} / \mathrm{WO}_{3}$ heterostructure may lead to a significant charge redistribution at the interface. To explore the charge transfer process in the heterostructure, the charge density difference is calculated and plotted in Fig.7 with an isosurface value of $0.0046 \mathrm{e} / \AA^{3}$. The yellow and cyan isosurfaces denote the electron accumulation and electron depletion respectively. Our study reveals that a high electron depletion occurred from the $\mathrm{MoS}_{2}$ side of the heterojunction, resulting in hole-rich sites in this portion of the system, while strong charge accumulation on the $\mathrm{WO}_{3}$ surface, gave rise to electron-rich area. Thus, electrons are expected to be excited more efficiently from the electron-rich $\mathrm{WO}_{3}$ part of the heterojunction. On the other hand, an internal electric field produced from the charge imbalance at the interface may help in the separation of electron and hole from the photogenerated excitons. Additionally, $\mathrm{MoS}_{2}$ behaves as an electron acceptor in the heterostructure. Therefore, after the charge separation, electrons tend to accumulate in the $\mathrm{MoS}_{2}$ region, whereas holes will be accumulated in the region close to $\mathrm{WO}_{3}$ and are expected to participate more actively in the reduction and oxidation reaction process respectively. To gain a deeper insight into the charge redistribution process and the formation of a built-in electric field at the interface, which has a key role in the photogenerated charge transfer process ${ }^{33}$, we have estimated the work functions in pristine $\mathrm{WO}_{3}, \mathrm{MoS}_{2}$, and $\mathrm{WO}_{3} / \mathrm{MoS}_{2}$ heterostructure using the following relation:

$$
\Phi=E_{v a c}-E_{F}
$$

where $\mathrm{E}_{v a c}$ and $\mathrm{E}_{F}$ represent the energy of a stationary electron in a vacuum and the Fermi energy of semiconductor respectively. Here the vacuum energy is a constant potential far from the surface atomic layers of the system estimated by introducing sufficient empty space in the unit cell. The planar averaged electrostatic potential plots of $\mathrm{MoS}_{2}, \mathrm{WO}_{3}$ and $\mathrm{WO}_{3} / \mathrm{MoS}_{2}$ heterostructure in the direction perpendicular to the surface, displayed in Fig.8a-Fig.8c, from which we have estimated values of work functions are $4.76 \mathrm{eV}, 6.13 \mathrm{eV}$, and $5.25 \mathrm{eV}$ respectively. Note that, the Fermi level of $\mathrm{MoS}_{2}$ is in higher energy than that of $\mathrm{WO}_{3}$ as displayed in Fig. 8a and 8b. Therefore, when $\mathrm{WO}_{3}$ comes in contact with $\mathrm{MoS}_{2}$, the valence electrons of $\mathrm{MoS}_{2}$ will start migrating towards the $\mathrm{WO}_{3}$ side, until the Fermi levels of these semiconductors are aligned. As a result, at the equilibrium, a built-in electric field directed from $\mathrm{MoS}_{2}$ to $\mathrm{WO}_{3}$ surface will be established. The existence of interfacial built-in potential will help to promote the separation of photogenerated electron-hole pairs, thereby inhibiting their recombination rate and subsequently improve the photocatalytic activity in the heterostructure. Thus, the occurrence of built-in potential at the $\mathrm{WO}_{3} / \mathrm{MoS}_{2}$ heterostructure interface may be one of the main key factors that help to enhance its photocatalytic performance. 

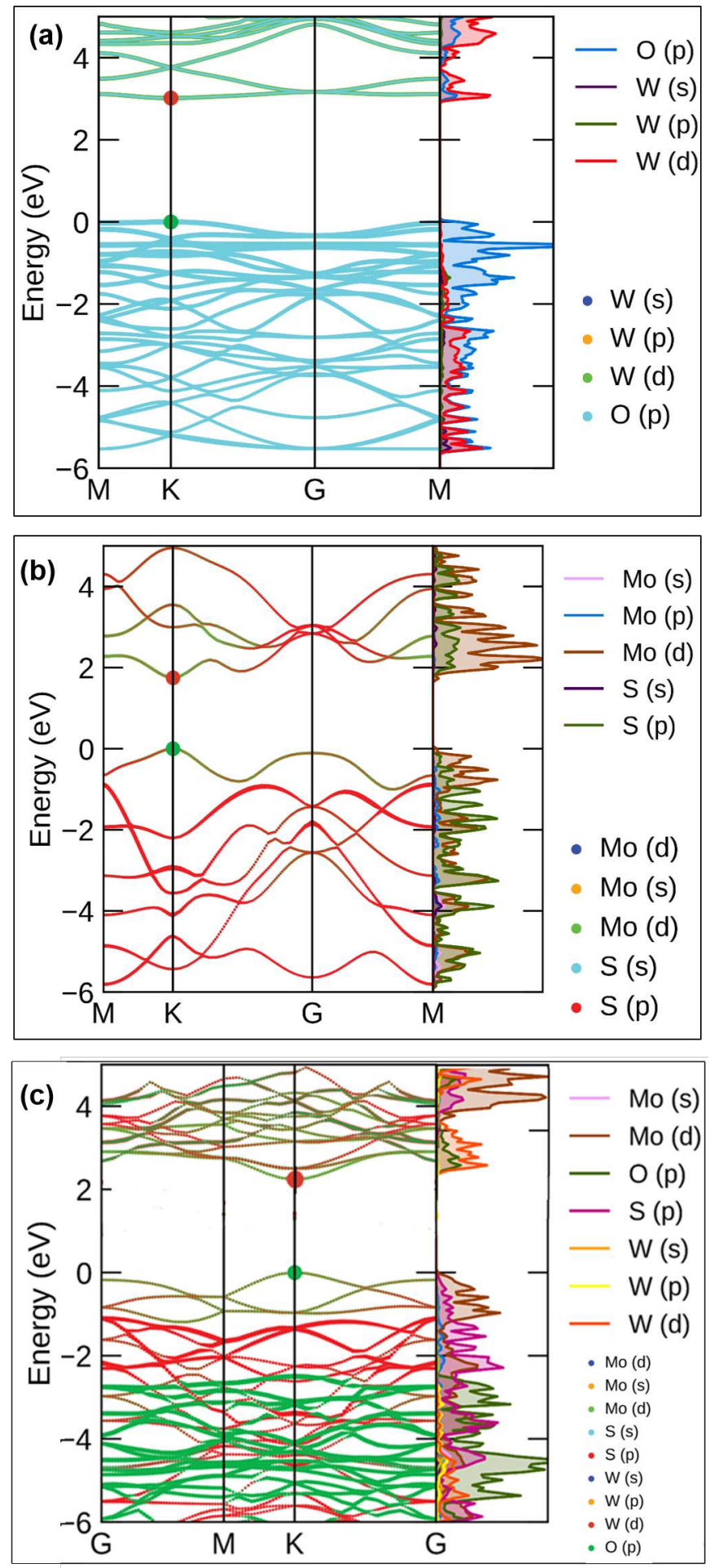

Figure 5. Calculated band structures and atom projected density of state plots of (a) $\mathrm{WO}_{3}$ monolayer (b) $\mathrm{MoS}_{2}$ monolayer and (c) $\mathrm{WO}_{3} / \mathrm{MoS}_{2}$ heterostructure within the hybrid HSE06 functional. The Fermi energy is shifted to $E=0$ in each plot.

\subsubsection{Visible light driven photocatalytic degradation of methylene blue}

The photocatalytic activity of pristine and heterostructure samples are evaluated from their dye degradation ability under visible light irradiation. We have used methylene blue dye and photodegraded it in presence of as-synthesized $\mathrm{MoS}_{2}, \mathrm{WO}_{3}$, and $\mathrm{WO}_{3} / \mathrm{MoS}_{2}$ photocatalysts. Upon visible light irradiation, there is a gradual decrease in the absorption peak of MB centered at $665 \mathrm{~nm}$, indicative of the reduction in its concentration as presented in Fig.9a. The plot presented in Fig.9b depicts the 


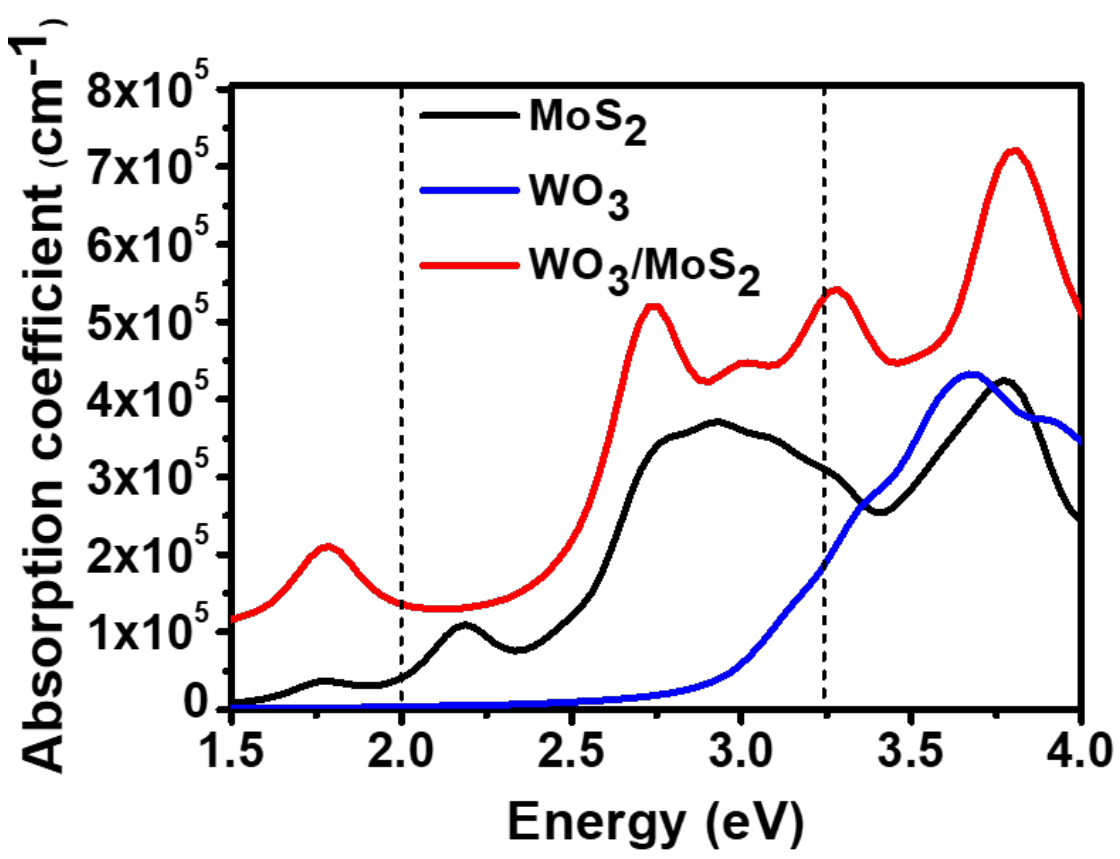

Figure 6. The calculated absorption coefficients of $\mathrm{MoS}_{2}, \mathrm{WO}_{3}$ and $\mathrm{WO}_{3} / \mathrm{MoS}_{2}$ heterostructure.

variation in the concentration of $\mathrm{MB}$ with respect to the visible light irradiation time in the presence of various photocatalysts. The negligible photodegradation of $\mathrm{MB}$ in the absence of any photocatalyst as shown by magenta-colored points indicates its high chemical stability. In presence of pristine $\mathrm{WO}_{3}$, even after $120 \mathrm{~min}$ of visible light irradiation, the degradation of MB was limited to just $85 \%$. On the contrary, the photodegradation of MB slightly improved as its concentration dropped to $12 \%$ after $100 \mathrm{~min}$ of visible light irradiation under the same conditions in the presence of pristine $\mathrm{MoS}_{2}$. On the other hand, in the presence of $\mathrm{WO}_{3} / \mathrm{MoS}_{2}$ nanocomposite, the concentration of $\mathrm{MB}$ reduced below $10 \%$, i.e, over $90 \%$ photodegradation was achieved in just 60 min under the visible light irradiation. The photodegradation rates of $\mathrm{MB}$, in presence of different catalysts, were computed using the pseudo-first-order kinetics given by the equation,

$$
\ln \frac{C_{\circ}}{C_{t}}=k_{a p p} t
$$

where $\mathrm{C}_{\mathrm{o}}, \mathrm{C}_{t}$ and $\mathrm{k}_{a p p}$ correspond to the initial concentration, the concentration at time $t$ and the apparent pseudo-first-order rate constant $\left(\mathrm{k}_{\text {app }}, \mathrm{min}^{-1}\right)$, respectively ${ }^{34}$. Plots of the pseudo-first-order reaction kinetics corresponding to as-synthesized photocatalysts are presented in Fig.10. Rate constant for the photodegradation of MB that were determined from the experimental data are $0.0909,0.3281$ and $0.7635 \mathrm{~min}^{-1}$ for $\mathrm{WO}_{3}, \mathrm{MoS}_{2}$ and $\mathrm{WO}_{3} / \mathrm{MoS}_{2}$ composite respectively. The value of the rate constant has been increased by almost one order of magnitude in the case of the composite system in comparison to the pristine $\mathrm{WO}_{3}$ and $\mathrm{MoS}_{2}$ photocatalysts, which confirms the excellent photocatalytic performance of the heterostructure.

\subsubsection{Hydrogen Evolution Reaction}

In the final step of our study, we have investigated the possibility of using this composite for photocatalytic water splitting. The chemical reactions involved in the water splitting process can be divided into two half-cell reactions, namely Hydrogen Evolution Reaction (HER) and Oxygen Evolution Reaction (OER). The HER can be explained through the Volmer-Tafel and Volmer-Heyrovsky mechanisms ${ }^{35}$. In the Volmer reaction, surface adsorbed hydrogen is formed through reduction of protons, viz. $H_{(a q)}^{+}+e^{-} \rightarrow H_{a d s}$. Volmer step is subsequently followed by Tafel or Heyrovsky step to complete the HER. In the Volmer-Tafel reaction mechanism, a hydrogen molecule $\left(\mathrm{H}_{2}\right)$ is formed when two adjacent adsorbed hydrogen atoms are combined over the electrode surface $H_{a d s}+H_{a d s} \rightarrow \mathrm{H}_{2}$. While in Volmer-Heyrovsky reaction, a proton present in water reacts 

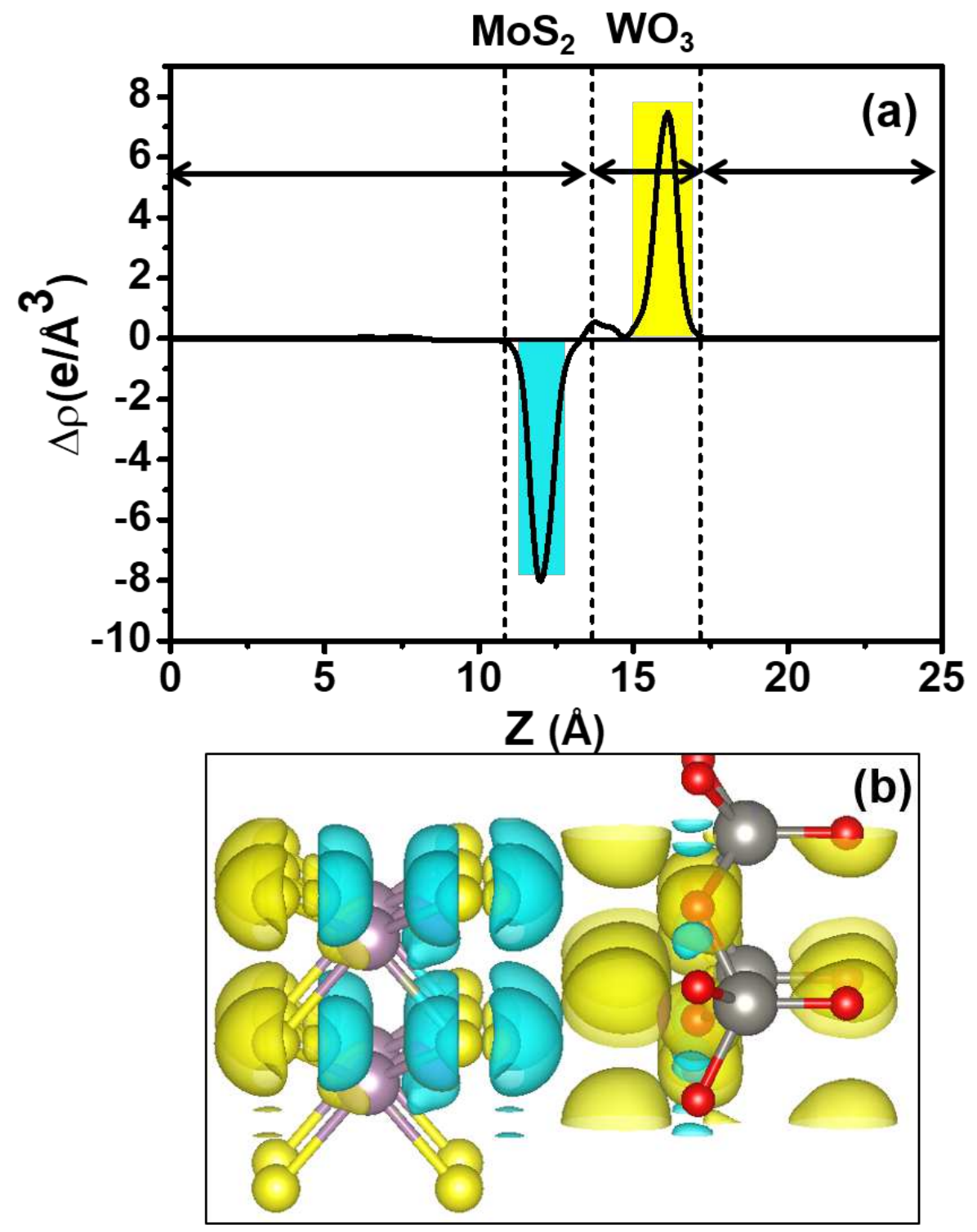

Figure 7. Charge density difference of $\mathrm{WO}_{3} / \mathrm{MoS}_{2}$ heterostructure within the hybrid HSE06 functional.

with surface adsorbed hydrogen to generate $\mathrm{H}_{2}$ viz. $H_{a d s}+H_{(a q)}^{+}+e^{-} \rightarrow \mathrm{H}_{2}{ }^{11,36}$. Thus, both the reaction mechanisms reveal that the adsorption energy of the hydrogen atom plays a critical role in determining the catalytic activity over the surface of the catalyst $^{37,38}$. Also, $H_{a d s}$ is related to the adsorption free energy $\left(\Delta \mathrm{G}_{H}\right)$ by the following equation:

$$
\Delta G_{H}=\Delta E_{a d s}+\Delta E_{Z P E}+T \Delta S_{H}
$$

where $E_{a d s}$ is the adsorption energy, $\Delta \mathrm{E}_{Z P E}$ is the zero-point energy difference of $\mathrm{H}_{2}$ in the adsorbed and gas phase state and its values ranging from $0.01-0.04 \mathrm{eV} . T$ is the temperature in $\mathrm{K}, \Delta \mathrm{S}_{H}$ is the change in the entropy between hydrogen in the adsorbed and gas phase can be express as $\Delta \mathrm{S}_{\mathrm{H}} \cong \frac{1}{2} \Delta S_{\mathrm{H}_{2}}^{o}$ where $\Delta S_{\mathrm{H}_{2}}^{o}$ is the entropy of $\mathrm{H}_{2}$ in gas phase at standard conditions ${ }^{37,39}$. At room temperature the energy value associated with the change in $\Delta \mathrm{S}_{H}$ is about $0.2 \mathrm{eV}$. Thus considering these values of $\Delta \mathrm{E}_{Z P E}$ and $\Delta \mathrm{S}_{H}$, the above equation reduces to $\Delta \mathrm{G}_{H}=\Delta E_{a d s}+0.24 \mathrm{eV}$. For an optimal HER catalyst, $\Delta \mathrm{G}_{H} \cong 0 \mathrm{eV}$ and hence the $\Delta E_{a d s}$ should be of the order of $-0.24 \mathrm{eV}$, where the binding strength of hydrogen is neither too strong nor too weak obeying the Sabatier principle ${ }^{40}$. The adsorption energy of hydrogen on different surface has been calculated by using the following equation:

$$
\Delta E_{a d s}=E_{S+n H}-E_{S}-\frac{n}{2} H_{2}
$$



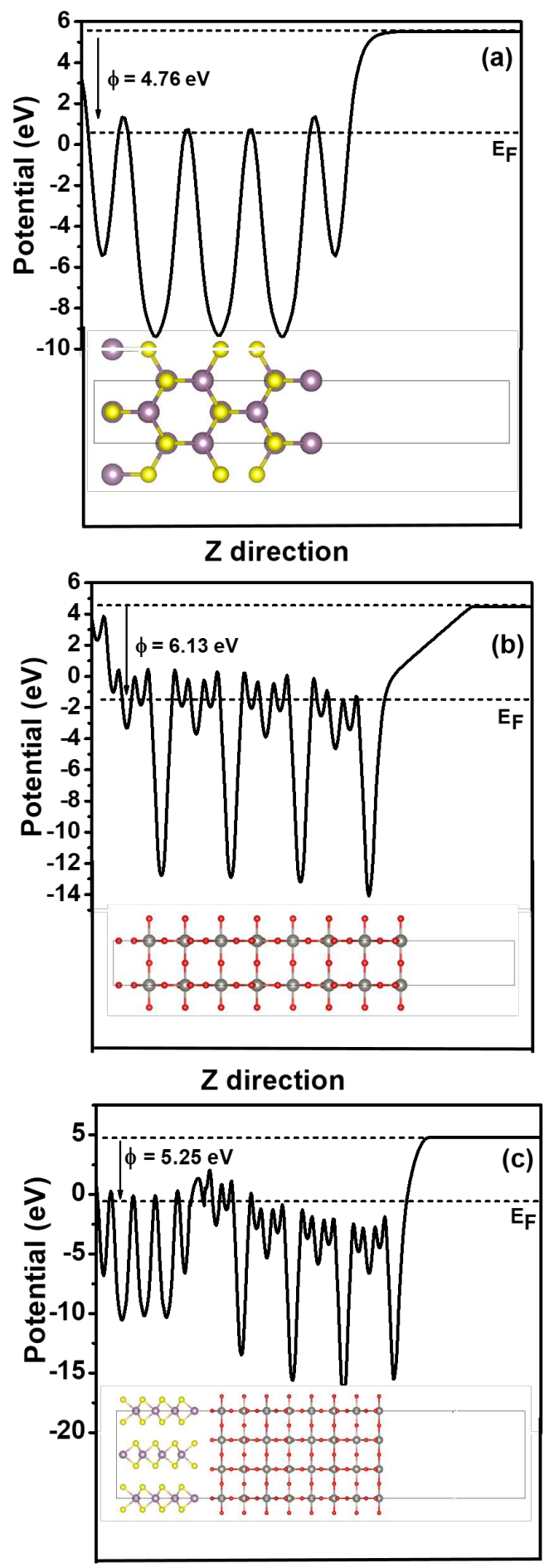

$Z$ direction

Figure 8. The work function of (a) $\mathrm{MoS}_{2}$, (b) $\mathrm{WO}_{3}$ and (c) $\mathrm{WO}_{3} / \mathrm{MoS}_{2}$ heterostructure. The dotted lines inside the potential plot denote the Fermi level and the vacuum energy level respectively.

here, $E_{S+n H}$ and $E_{S}$ represent the calculated total energies of the system with and without adsorbed hydrogen respectively. $n$ is the number of hydrogen atoms that are present in the unit cell, in the present case $n=1$. Since adsorption of $\mathrm{H}$ can be done at different sites, the $\mathrm{H}$ atom was initially placed on-top position of the semiconductor surface and its atomic position was allowed 

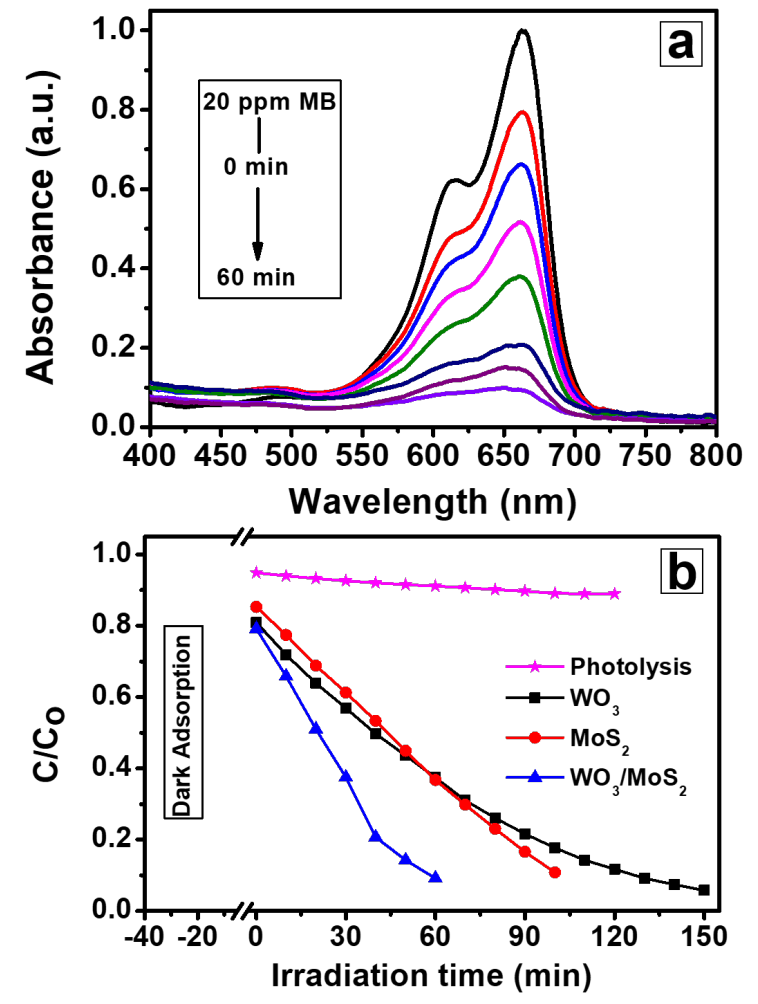

Figure 9. (a) UV-vis absorption spectra depicting the visible light induced photodegradation of methylene blue in the presence of $\mathrm{WO}_{3} / \mathrm{MoS}_{2}$ photocatalyst (b) Plot depicting the time dependent photodegradation of methylene blue under visible light irradiation in the presence of as-synthesized $\mathrm{WO}_{3}, \mathrm{MoS}_{2}$ and $\mathrm{WO}_{3} / \mathrm{MoS}_{2}$ as photocatalysts.

to relax without any constraints imposed on it. The atomic positions of the rest of the atoms were also allowed to relax inside the fixed unit cell The energy-optimized positions of the $\mathrm{H}$ atom after the atomic relaxation of all the above-mentioned systems are represented in Fig.11. The calculated $\Delta E_{a d s}$ and $\Delta G_{H}$ values for $\mathrm{MoS}_{2}, \mathrm{WO}_{3}$ and $\mathrm{WO}_{3} / \mathrm{MoS}_{2}$ are presented in Table 2. The obtained result shows that $\Delta G_{H}$ is very close to zero for the heterostructure indicates that an excellent photocatalytic HER performance can be achieved using this composite.

\subsubsection{Proposed photocatalytic mechanism}

The mechanism of photocatalysis depends mainly on the generation, separation, transfer, and participation of photogenerated charge carriers during the catalytic process ${ }^{41}$. The band edge positions of the photocatalysts that are the most crucial parameters in these processes are determined based on the following equations:

$$
\begin{gathered}
E_{V B}=\chi-E_{e}+\frac{1}{2} E_{g} \\
E_{C B}=E_{V B}-E_{g}
\end{gathered}
$$

here $E_{g}$ represents the bandgap of the system, $E_{e}$ is the energy of free electrons in the hydrogen scale $(4.5 \mathrm{eV}), \chi$ is the absolute electronegativity of the semiconductor, $E_{V B}$ and $E_{C B}$ are the $\mathrm{VB}$ and $\mathrm{CB}$ edge potentials, respectively ${ }^{42}$. The $\chi$ values of $\mathrm{WO}_{3}$ and $\mathrm{MoS}_{2}$ are calculated to be 6.59 and 5.32 respectively ${ }^{43}$. The calculated CB and VB positions of $\mathrm{WO}_{3}$ and $\mathrm{MoS}_{2}$ in $\mathrm{NHE}^{-}$ scale are presented in Table 1 and a diagram indicating relative positions of band edges are shown in Fig.12.

It is clear from the band diagram that the heterojunction forms a type-II staggered band alignment, which is favorable for the separation and transfer process of photogenerated charge carriers. While using this heterostructure in the conventional electron-hole separation process, one can expect that the photogenerated electrons accumulated in the $\mathrm{CB}_{\text {of }} \mathrm{MoS}_{2}$ tend to move to the $\mathrm{CB}$ of $\mathrm{WO}_{3}$ as the $\mathrm{CB}$ position of $\mathrm{MoS}_{2}$ is more negative with respect to $\mathrm{WO}_{3}$. Meanwhile, the holes present in 


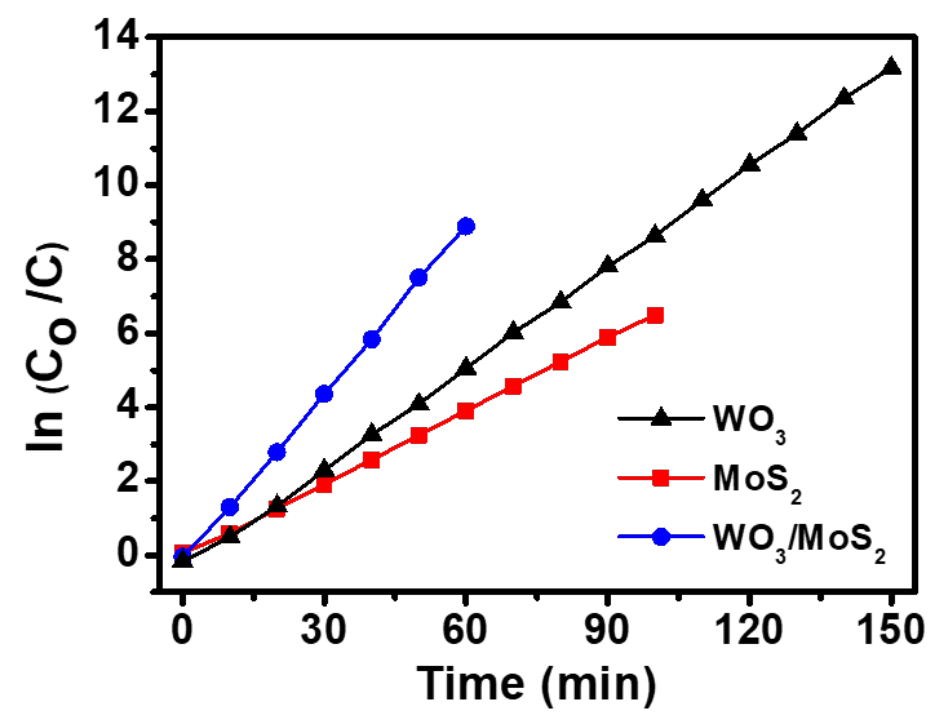

Figure 10. Pseudo first-order reaction kinetics plot of methylene blue photodegradation using $\mathrm{WO}_{3}, \mathrm{MoS}_{2}$ and $\mathrm{WO}_{3} / \mathrm{MoS}_{2}$ as photocatalysts.

Table 2. Calculated adsorption energies $\left(\Delta E_{a d s}\right)$ and adsorption free enrgy of $\mathrm{H}\left(\Delta G_{H}\right)$ of pristine $\mathrm{MoS}_{2}, \mathrm{WO}_{3}$ and $\mathrm{WO}_{3} / \mathrm{MoS}_{2}$ heterostructure.

\begin{tabular}{ccc}
\hline System & $\begin{array}{c}\Delta E_{a d s} \\
(\mathrm{eV})\end{array}$ & $\begin{array}{c}\Delta G_{H} \\
(\mathrm{eV})\end{array}$ \\
\hline $\mathrm{WO}_{3}$ & -2.10 & -1.86 \\
$\mathrm{MoS}_{2}$ & -0.72 & -0.48 \\
$\mathrm{WO}_{3} / \mathrm{MoS}_{2}$ heterostructure & -0.26 & -0.03 \\
\hline
\end{tabular}

the $\mathrm{VB}$ of $\mathrm{WO}_{3}$ will migrate to the $\mathrm{VB}$ of $\mathrm{MoS}_{2}$ under visible light irradiation, as the $\mathrm{VB}$ position of $\mathrm{WO}_{3}$ is more positive compared to $\mathrm{MoS}_{2}$.

However, note that the potential of the $\mathrm{CBM}$ of $\mathrm{WO}_{3}(0.59 \mathrm{eV})$ is lower than the potential required for $\mathrm{O}_{2}$ generation $\left(\mathrm{O}_{2} /{ }^{\bullet} \mathrm{O}_{2}{ }^{-}=-0.33 \mathrm{eV}\right.$ vs. NHE), thus electrons on the $\mathrm{CB}$ of $\mathrm{WO}_{3}$ cannot reduce $\mathrm{O}_{2}$ into superoxide anion radical $\left({ }^{\bullet} \mathrm{O}_{2}{ }^{-}\right)$. Also, the VBM potential of $\mathrm{MoS}_{2}(1.69 \mathrm{eV})$ is lower than the $\mathrm{H}_{2} \mathrm{O} /{ }^{\bullet} \mathrm{OH}$ redox potential $(2.68 \mathrm{eV}$ vs. NHE) and hence the holes on the VB of $\mathrm{MoS}_{2}$ are unable to oxidize the adsorbed water molecules to hydroxyl radical $\left({ }^{\bullet} \mathrm{OH}\right)$. Similarly, the photoinduced electrons over the $\mathrm{CB}$ of $\mathrm{WO}_{3}$ cannot reduce $\mathrm{H}^{+}$to $\mathrm{H}_{2}$ as its $\mathrm{CBM}$ potential is lower than the $\mathrm{H}^{+} / \mathrm{H}_{2} \mathrm{O}(0 \mathrm{~V}$ vs. NHE) potential, while the VBM potential of $\mathrm{MoS}_{2}$ is not lower than the $\mathrm{O}_{2} / \mathrm{H}_{2} \mathrm{O}\left(1.23 \mathrm{~V}\right.$ vs. NHE), indicating that it can produce $\mathrm{O}_{2}$. Therefore, if the separation and transfer of the photoinduced charge carriers in the $\mathrm{WO}_{3} / \mathrm{MoS}_{2}$ heterostructure occurs via the conventional heterojunction process, the formation of ${ }^{\bullet} \mathrm{O}_{2}{ }^{-}$and ${ }^{\bullet} \mathrm{OH}$ reactive species and generation of $\mathrm{H}_{2}$ are not favorable, resulting in lower photocatalytic activity. Hence, it can be realized that the $\mathrm{WO}_{3} / \mathrm{MoS}_{2}$ heterostructure follows a typical Z-scheme charge transfer mechanism rather than the conventional process.

\section{Discussion}

Formation of the $\mathrm{WO}_{3} / \mathrm{MoS}_{2}$ heterostructure causes electrons to transfer from $\mathrm{MoS}_{2}$ to $\mathrm{WO}_{3}$ through intimate contact interface owing to the more negative Fermi level of $\mathrm{MoS}_{2}$, thereby leaving holes on the surface of $\mathrm{MoS}_{2}$. This electron diffusion continued until the Fermi levels are equilibrated ${ }^{4,45}$. As a result, an internal electric field directed from $\mathrm{MoS}_{2}$ to $\mathrm{WO}_{3}$ part 
(a)
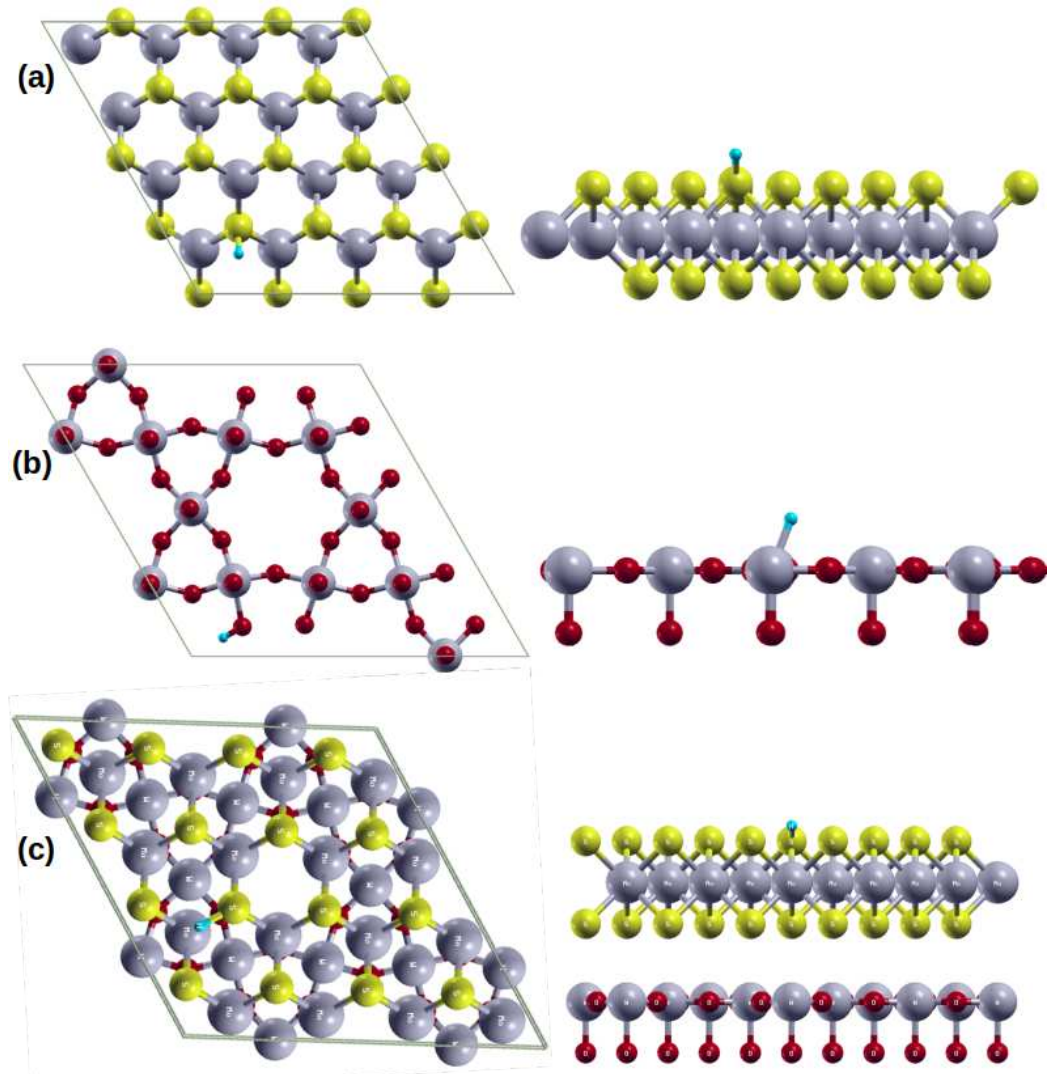

Top View

Side View

Figure 11. Energy optimized geometric structure of $\mathrm{H}$ adsorbed on (a) $\mathrm{MoS}_{2}$, (b) $\mathrm{WO}_{3}$ and (c) $\mathrm{WO}_{3} / \mathrm{MoS}_{2}$ heterojunction.

of the heterostructure was formed at the interface (as represented in work function analysis). This field basically suppresses the migration of photogenerated electrons from $\mathrm{MoS}_{2} \mathrm{CB}$ to $\mathrm{WO}_{3} \mathrm{CB}$ and photogenerated holes from $\mathrm{WO}_{3} \mathrm{VB}$ to $\mathrm{MoS}_{2} \mathrm{VB}$. On the contrary, the electron transfer process is carried out along the Z-direction from $\mathrm{WO}_{3} \mathrm{CB}$ to $\mathrm{MoS}_{2} \mathrm{VB}$, resulting in the accumulation of photoexcited electrons in the $\mathrm{MoS}_{2} \mathrm{CB}$ and photoexcited holes in the $\mathrm{WO}_{3} \mathrm{VB}$. The more positive VB potential of $\mathrm{WO}_{3}\left(3.59 \mathrm{eV}\right.$, compared to the $\mathrm{H}_{2} \mathrm{O} /{ }^{\bullet} \mathrm{OH}$ potential) can easily oxidize the water molecules to ${ }^{\bullet} \mathrm{OH}$ radicals. Similarly, ${ }^{\bullet} \mathrm{O}_{2}{ }^{-}$ radicals are produced over more negative $\mathrm{CB}$ of $\mathrm{MoS}_{2}$. Thus, the generation of these reactive species may induce a higher redox ability in the heterostructure, and enhance its photocatalytic performance in comparison to the pristine photocatalysts. On the other hand, the band alignment of $\mathrm{WO}_{3} / \mathrm{MoS}_{2}$ heterostructure with reference to the standard hydrogen electrode shows that the $\mathrm{MoS}_{2} \mathrm{CB}$ potential is more negative compared to the $\mathrm{H}^{+} / \mathrm{H}_{2}$ and has ability to reduce $\mathrm{H}^{+}$to $\mathrm{H}_{2}$. Also, the VB potential of $\mathrm{WO}_{3}$ is more positive compared to the $\mathrm{O}_{2} / \mathrm{H}_{2} \mathrm{O}$ and can easily generate ${ }^{\bullet} \mathrm{O}_{2}{ }^{-}$radicals. Comparing the relative band edges of $\mathrm{WO}_{3}$ and $\mathrm{MoS}_{2}$ to the redox potentials, the $\mathrm{WO}_{3} / \mathrm{MoS}_{2}$ heterostructure forms a typical Z-scheme photocatalyst for the overall water splitting process. Thus, the construction of direct Z-scheme photocatalyst benefits the separation of photoexcited charge carriers at the $\mathrm{WO}_{3} / \mathrm{MoS}_{2}$ interface. Moreover, the strong electron reducibility of $\mathrm{MoS}_{2}$ and strong hole oxidizability of $\mathrm{WO}_{3}$ are maintained, which further improves the photocatalytic performance.

To conclude, we have synthesized a noble semiconductor heterostructure namely $\mathrm{WO}_{3} / \mathrm{MoS}_{2}$ via hydrothermal approach and performed an in-depth investigation of its photocatalytic properties using the various experimental technique along with first-principles density functional theory calculations. The structural, electronic, optical, and charge transfer properties of the heterostructure are investigated in detail using accurate DFT calculations. Our study reveals that a built-in electric field 


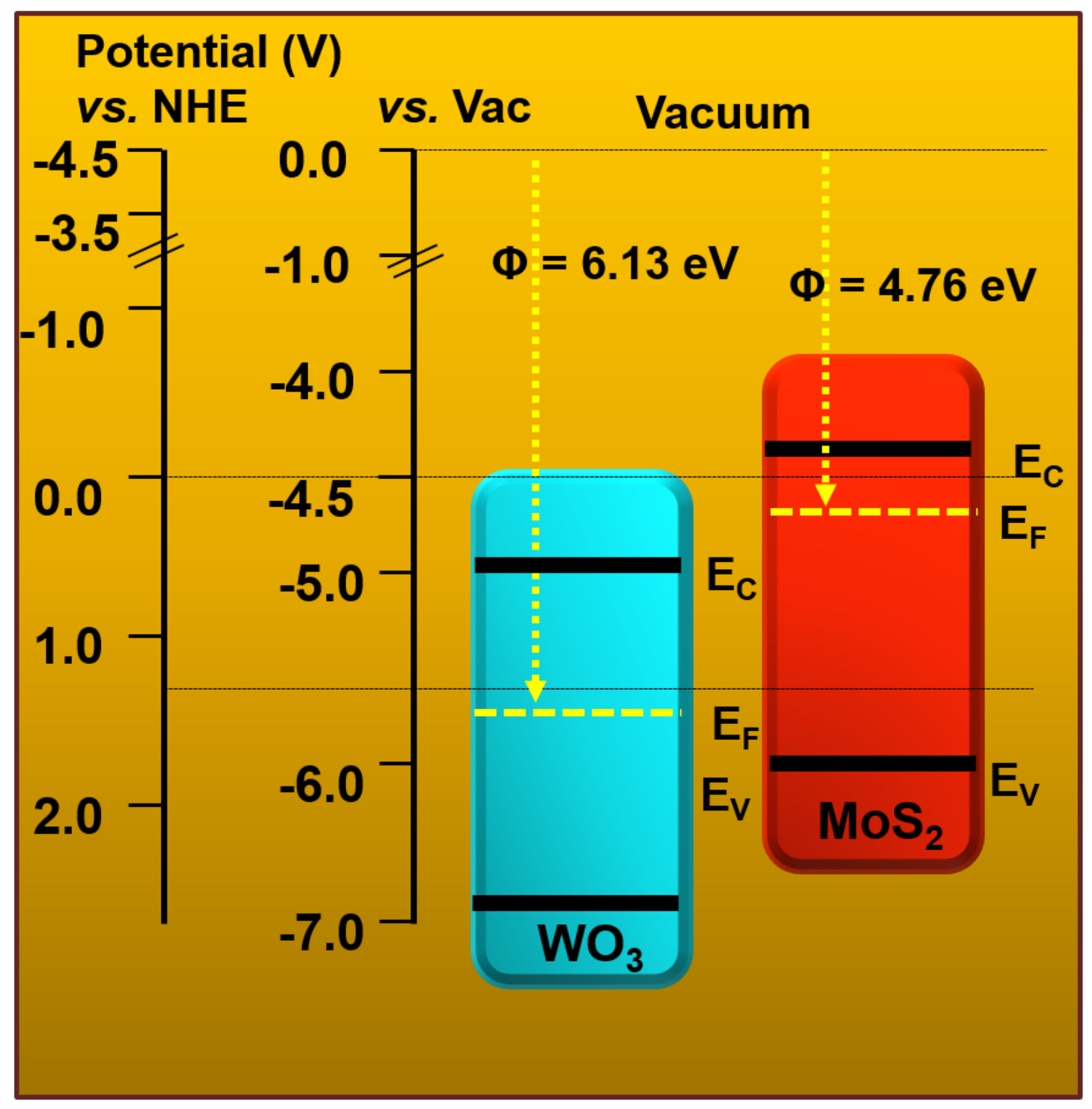

Figure 12. Calculated band alignment in $\mathrm{WO}_{3} / \mathrm{MoS}_{2}$ heterostructure.

produces near the interface of this heterostructure helps to separate photogenerated electrons and holes more efficiently and leaves them to accumulate at the different parts of the composite. As a result, the recombination rate reduces which in turn enhances the photocatalytic activity. The theoretical results reciprocate our experimental outcome of photodegradation of methylene blue under visible light irradiation. The work function, charge density difference, and accurate band edge positions were estimated which indicate that it follows a Z-scheme charge transfer mechanism during the photocatalytic reaction process. The catalytic activity towards HER has been further investigated considering dispersion corrected DFT. The calculated $\Delta G_{H}$ in case of heterostructure were found to be very close to the thermo-neutral point $\Delta G_{H}=0 \mathrm{eV}$ indicating that its activity towards HER would significantly improve owing to the formation of Z-scheme heterostructure. The advantages of the insights gained through this work are two-fold. First, the mechanism and origin of the photocatalytic activity can be rationalized. Second, it is expected to provide new insights that can contribute to the rational design of new materials for multifunctional applications. 


\section{Methods}

\subsection{Experimental details}

0.1.1 Materials used

Sodium tungstate dihydrate $\left(\mathrm{Na}_{2} \mathrm{WO}_{4} \cdot 2 \mathrm{H}_{2} \mathrm{O}\right)$, sodium chloride $(\mathrm{NaCl})$, hydrochloric acid $(\mathrm{HCl})$, sodium molybdate $\left(\mathrm{Na}_{2} \mathrm{MoO}_{4} \cdot 2 \mathrm{H}_{2} \mathrm{O}\right)$, thiourea $\left(\mathrm{CH}_{4} \mathrm{~N}_{2} \mathrm{~S}\right)$ and glucose $\left(\mathrm{C}_{6} \mathrm{H}_{12} \mathrm{O}_{6}\right)$ of the purest grade available were purchased from Merck and used without further purification. Methylene blue $\left(\mathrm{C}_{16} \mathrm{H}_{18} \mathrm{ClN}_{3} \mathrm{~S}\right)$ was procured from Sigma-Aldrich. Deionized (DI) water from a Milli-Q (18 $\mathrm{M} \Omega \mathrm{cm}$ ) ultrapure system was used throughout the experiments.

\subsubsection{Synthesis of $\mathrm{WO}_{3}$}

$\mathrm{WO}_{3}$ was prepared via the hydrothermal method by adapting the similar process reported $\mathrm{in}^{29}$, with $\mathrm{NaCl}$ as a capping agent. In a typical synthesis, $3.30 \mathrm{~g}$ of $\mathrm{Na}_{2} \mathrm{WO}_{4} \cdot 2 \mathrm{H}_{2} \mathrm{O}$ and $1.16 \mathrm{~g}$ of NaCl were dissolved in $75 \mathrm{ml}$ of DI water, and the $\mathrm{pH}$ of the solution was adjusted to 2.5 using $3 \mathrm{~mol} \mathrm{~L}^{-1} \mathrm{HCl}$ aqueous solution. The above solution was transferred into a Teflon-lined stainless steel autoclave which was placed in an electric oven at $180^{\circ} \mathrm{C}$ for $24 \mathrm{~h}$ after which it was allowed to cool down before the white precipitates were collected. The final precipitate was washed thoroughly with DI water and absolute ethanol and dried in an oven at $80^{\circ} \mathrm{C}$ for $12 \mathrm{~h}$ to get $\mathrm{WO}_{3}$.

\subsubsection{Synthesis of $\mathrm{WO}_{3} / \mathrm{MoS}_{2}$ nanocomposites}

Next, the as-prepared $\mathrm{WO}_{3}(0.1 \mathrm{~g})$ was dispersed in $40 \mathrm{ml}(0.5 \mathrm{M})$ glucose solution under ultrasonication for $10 \mathrm{~min}$. Then $0.4 \mathrm{~g}$ of sodium molybdate and $0.8 \mathrm{~g}$ of thiourea were added to the above solution and magnetically stirred for an hour. The obtained solution was transferred into a Teflon-lined stainless steel autoclave which was placed in an electric oven at $200{ }^{\circ} \mathrm{C}$ for $10 \mathrm{~h}$ after which it was allowed to cool down to room temperature. The final precipitate was washed thoroughly with DI water and absolute ethanol and dried in an oven at $80^{\circ} \mathrm{C}$ for $12 \mathrm{~h}$ to get $\mathrm{WO}_{3} / \mathrm{MoS}_{2}$. For comparison, the pure $\mathrm{MoS}_{2}$ was synthesized under the same experimental conditions ${ }^{30}$.

\subsubsection{Characterization}

The crystallinity of the as-synthesized photocatalysts was studied by powder X-ray diffraction (XRD) using a Rigaku miniflex $600 \mathrm{X}$-ray diffractometer with $\mathrm{Cu} \mathrm{K} \alpha$ radiation $(\lambda=1.5518 \AA)$ in the range $2 \theta$ of $10^{\circ}-80^{\circ}$ at a scan rate of $5^{\circ} \mathrm{min}^{-1}$. A field emission scanning electron microscope ZIESS Sigma equipped with an energy dispersive X-ray spectrometer (EDS) was used for morphological and compositional analysis. UV-Vis diffuse reflectance spectra (DRS) was determined by Varian Cary 5000 UV-Vis spectrophotometer.

\subsubsection{Photocatalytic degradation of methylene blue}

The photocatalytic performance of the as-prepared photocatalysts was assessed by monitoring MB degradation with a $70 \mathrm{~W}$ CDM-R lamp ( 830 PAR3OL 40D, Philips, 4600 lumens, $\lambda \geq 400 \mathrm{~nm}$ ) as the visible light source. The reaction slurry was prepared by suspending $200 \mathrm{mg}$ of photocatalyst in an aqueous solution containing $200 \mathrm{ml}$ of MB (10 ppm) in a crystallizing dish (Duran $\AA$ ) of $300 \mathrm{ml}$ capacity. Before illumination, the slurry was allowed to stir in dark for $30 \mathrm{~min}$ to ensure the adsorption of MB on the surface of the photocatalysts. The degradation of MB was examined by withdrawing aliquots (5 ml) of the reaction slurry at regular intervals of time, centrifuged for separating the photocatalyst and their absorption spectrum was recorded using a UV-Vis spectrophotometer (SD 2000, Ocean Optics). To maintain consistency, all experiments were performed in triplicate. Finally, the rate of degradation was determined from the change in absorbance of MB solution. Decrease in the absorbance of $\mathrm{MB}$ with respect to irradiation time was used to determine the efficiency of the photocatalysts that were calculated using the equation,

$$
\operatorname{Efficiency}(\%)=\frac{C_{\circ}-C}{C_{\circ}} \times 100
$$

where $\mathrm{C}_{\circ}$ is the initial concentration and $\mathrm{C}$ is the concentration of the dye after light irradiation.

\subsection{Computational methodology}

The crystal and electronic structures of pristine and functionalized semiconductors were determined through density functional theory (DFT) calculations using the Vienna Ab initio Simulation Package (VASP), where the ion-electron interactions are described by the projected augmented wave (PAW) method. The exchange-correlation for electrons is represented by the generalized gradient approximation (GGA) functional based on the Perdew-Burke-Ernzerhof (PBE) form ${ }^{46-48}$. Owing to the fact that the dispersive forces are not well defined in the standard DFT and a non-local term needs to be added to account for these dispersive forces, we employed the latest dispersion correction (D3) of Grimme throughout our calculations to correctly describe the adsorption energy and long-range vdW interactions ${ }^{49}$. A kinetic energy cut-off of $500 \mathrm{eV}$ for the plane-wave basis set was applied, with an energy convergence of $1.0 \times 10^{-5} \mathrm{eV}$. For structural optimization, $0.01 \mathrm{eV} / \AA$ was taken as 
the force convergence criterion. A vacuum region of $10 \AA$ was exploited to avoid the interaction between periodic images of adjacent layers. In all our calculations, the first Brillouin zone integration was performed with $\Gamma$-centered $9 \times 9 \times 1 \mathrm{k}$-point grid. In order to obtain accurate electronic structures, we performed hybrid density functional calculations within the HSE06 approximation..$^{50}$. The short-range part of PBE exchange was weighted by $25 \%$ Hartree-Fock exchange. To calculate the adsorption energy of $\mathrm{H}$ atom on various functionalized surfaces, we used a $3 \times 3 \times 1$ supercell of $\mathrm{MoS}_{2}$ and $2 \times 2 \times 1$ supercell of $\mathrm{WO}_{3}$ respectively.

\section{References}

1. Zhu, J. et al. Boundary activated hydrogen evolution reaction on monolayer mos 2. Nat. communications 10, 1-7 (2019).

2. Dai, Z. et al. Hexagonal-phase cobalt monophosphosulfide for highly efficient overall water splitting. ACS nano 11, 11031-11040 (2017).

3. Voiry, D., Yang, J. \& Chhowalla, M. Recent strategies for improving the catalytic activity of $2 \mathrm{~d}$ tmd nanosheets toward the hydrogen evolution reaction. Adv. Mater. 28, 6197-6206 (2016).

4. Sabatier, P. La catalyse en chimie organique (Nouveau Monde éditions, 2014).

5. Hinnemann, B. et al. Biomimetic hydrogen evolution: Mos2 nanoparticles as catalyst for hydrogen evolution. J. Am. Chem. Soc. 127, 5308-5309 (2005).

6. Tan, T. L., Wang, L.-L., Johnson, D. D. \& Bai, K. Hydrogen deposition on pt (111) during electrochemical hydrogen evolution from a first-principles multiadsorption-site study. The J. Phys. Chem. C 117, 22696-22704 (2013).

7. Hu, W.-H. et al. Ultrathin mos2-coated carbon nanospheres as highly efficient electrocatalyts for hydrogen evolution reaction. Int. J. Hydrog. Energy 40, 6552-6558 (2015).

8. Ye, G. et al. Defects engineered monolayer mos2 for improved hydrogen evolution reaction. Nano letters 16, 1097-1103 (2016).

9. Chua, X. J. et al. Negative electrocatalytic effects of p-doping niobium and tantalum on mos 2 and ws 2 for the hydrogen evolution reaction and oxygen reduction reaction. ACS Catal. 6, 5724-5734 (2016).

10. Ouma, C. N. M., Obodo, K. O., Braun, M., Amolo, G. O. \& Bessarabov, D. Insights on hydrogen evolution reaction in transition metal doped monolayer tcs2 from density functional theory calculations. Appl. Surf. Sci. 470, 107-113 (2019).

11. Mir, S. H. et al. A comparative study of hydrogen evolution reaction on pseudo-monolayer ws 2 and pts 2: insights based on the density functional theory. Catal. Sci. \& Technol. 7, 687-692 (2017).

12. Liu, D. et al. Hydrogen evolution activity enhancement by tuning the oxygen vacancies in self-supported mesoporous spinel oxide nanowire arrays. Nano Res. 11, 603-613 (2018).

13. Chen, J. et al. Wo3-x nanoplates grown on carbon nanofibers for an efficient electrocatalytic hydrogen evolution reaction. ACS applied materials \& interfaces 8, 18132-18139 (2016).

14. Datta, R. et al. Highly active two dimensional $\alpha$-moo 3- $\mathrm{x}$ for the electrocatalytic hydrogen evolution reaction. J. Mater. Chem. A 5, 24223-24231 (2017).

15. Durán-Álvarez, J., Del Angel, R., Ramírez-Ortega, D., Guerrero-Araque, D. \& Zanella, R. An alternative method for the synthesis of functional au/wo3 materials and their use in the photocatalytic production of hydrogen. Catal. Today 341, 49-58 (2020).

16. Hu, G. et al. Enhanced electrocatalytic activity of wo3@ nprgo composite in a hydrogen evolution reaction. Appl. Surf. Sci. 463, 275-282 (2019).

17. Mohamed, M. M., Salama, T. M., Hegazy, M., Shahba, R. M. A. \& Mohamed, S. Synthesis of hexagonal wo3 nanocrystals with various morphologies and their enhanced electrocatalytic activities toward hydrogen evolution. Int. J. Hydrog. Energy 44, 4724-4736 (2019).

18. Omrani, N. \& Nezamzadeh-Ejhieh, A. A comprehensive study on the enhanced photocatalytic activity of cu2o/bivo4/wo3 nanoparticles. J. Photochem. Photobiol. A: Chem. 389, 112223 (2020).

19. Shang, X. et al. Novel ws $2 /$ wo 3 heterostructured nanosheets as efficient electrocatalyst for hydrogen evolution reaction. Mater. Chem. Phys. 197, 123-128 (2017).

20. Isari, A. A. et al. Sono-photocatalytic degradation of tetracycline and pharmaceutical wastewater using wo3/cnt heterojunction nanocomposite under us and visible light irradiations: A novel hybrid system. J. Hazard. Mater. 390, 122050 (2020). 
21. Yu, W. et al. Direct z-scheme g-c3n4/wo3 photocatalyst with atomically defined junction for h2 production. Appl. Catal. B: Environ. 219, 693-704 (2017).

22. Hu, T., Li, P., Zhang, J., Liang, C. \& Dai, K. Highly efficient direct z-scheme wo3/cds-diethylenetriamine photocatalyst and its enhanced photocatalytic h2 evolution under visible light irradiation. Appl. Surf. Sci. 442, 20-29 (2018).

23. Cui, X. et al. Controlling pt co-catalyst loading in a wo3 quantum dot and mos 2 nanosheet composite z-scheme system for enhanced photocatalytic h2 evolution. Nanotechnology 31, 185701.

24. Zhang, L. et al. Z-scheme system of wo3@ mos2/cds for photocatalytic evolution h2: Mos2 as the charge transfer mode switcher, electron-hole mediator and cocatalyst. Appl. Catal. B: Environ. 259, 118073 (2019).

25. Li, G. et al. Graphene-bridged wo $3 / \operatorname{mos} 2$ z-scheme photocatalyst for enhanced photodegradation under visible light irradiation. Mater. Chem. Phys. 246, 122827 (2020).

26. Zeng, Y. et al. Degradation of bisphenol a using peroxymonosulfate activated by wo3@ mos2/ag hollow nanotubes photocatalyst. Chemosphere 227, 589-597 (2019).

27. Yin, W.-J. et al. Band structure engineering of semiconductors for enhanced photoelectrochemical water splitting: the case of tio 2. Phys. Rev. B 82, 045106 (2010).

28. Li, H., Guo, C., Xiong, Y. \& Yang, Y. Electric field induced band modulation of ws2-gec heterostructures for efficient photocatalytic water splitting: A density functional theory study. Mater. Chem. Phys. 244, 122732 (2020).

29. Zhang, H. et al. Tio 2 (b) nanoparticle-functionalized wo 3 nanorods with enhanced gas sensing properties. Phys. Chem. Chem. Phys. 16, 10830-10836 (2014).

30. Zeng, Y. et al. A novel route to manufacture wo $3 @$ mos 2 p-n heterostructure hollow tubes with enhanced photocatalytic activity. Chem. Commun. 55, 683-686 (2019).

31. Shenoy, S., Jang, E., Park, T. J., Gopinath, C. S. \& Sridharan, K. Cadmium sulfide nanostructures: Influence of morphology on the photocatalytic degradation of erioglaucine and hydrogen generation. Appl. Surf. Sci. 483, 696-705 (2019).

32. Zhang, J.-R., Zhao, Y.-Q., Chen, L., Yin, S.-F. \& Cai, M.-Q. Density functional theory calculation on facet-dependent photocatalytic activity of mos2/cds heterostructures. Appl. Surf. Sci. 469, 27-33 (2019).

33. Liu, J. Origin of high photocatalytic efficiency in monolayer g-c $3 n 4 / c d s$ heterostructure: a hybrid dft study. The J. Phys. Chem. C 119, 28417-28423 (2015).

34. Shenoy, S. \& Sridharan, K. Bismuth oxybromide nanoplates embedded on activated charcoal as effective visible light driven photocatalyst. Chem. Phys. Lett. 749, 137435 (2020).

35. Benck, J. D., Hellstern, T. R., Kibsgaard, J., Chakthranont, P. \& Jaramillo, T. F. Catalyzing the hydrogen evolution reaction (her) with molybdenum sulfide nanomaterials. Acs Catal. 4, 3957-3971 (2014).

36. Tsai, C., Chan, K., Nørskov, J. K. \& Abild-Pedersen, F. Rational design of mos 2 catalysts: tuning the structure and activity via transition metal doping. Catal. Sci. \& Technol. 5, 246-253 (2015).

37. Nørskov, J. K. et al. Trends in the exchange current for hydrogen evolution. J. The Electrochem. Soc. 152, J23-J26 (2005).

38. Koper, M. T. Thermodynamic theory of multi-electron transfer reactions: Implications for electrocatalysis. J. Electroanal. Chem. 660, 254-260 (2011).

39. Mir, S. H. et al. Two-dimensional boron: lightest catalyst for hydrogen and oxygen evolution reaction. Appl. Phys. Lett. 109, 053903 (2016).

40. Seh, Z. W. et al. Combining theory and experiment in electrocatalysis: Insights into materials design. Science 355, eaad4998 (2017).

41. Zhu, S. \& Wang, D. Photocatalysis: basic principles, diverse forms of implementations and emerging scientific opportunities. Adv. Energy Mater. 7, 1700841 (2017).

42. Opoku, F., Govender, K. K., van Sittert, C. G. C. E. \& Govender, P. P. Insights into the photocatalytic mechanism of mediator-free direct z-scheme g-c3n4/bi2moo6 (010) and g-c3n4/bi2wo6 (010) heterostructures: a hybrid density functional theory study. Appl. Surf. Sci. 427, 487-498 (2018).

43. Xu, Y. \& Schoonen, M. A. The absolute energy positions of conduction and valence bands of selected semiconducting minerals. Am. Mineral. 85, 543-556 (2000).

44. Liu, J., Cheng, B. \& Yu, J. A new understanding of the photocatalytic mechanism of the direct z-scheme gc 3 n $4 /$ tio 2 heterostructure. Phys. Chem. Chem. Phys. 18, 31175-31183 (2016). 
45. Meng, A., Zhu, B., Zhong, B., Zhang, L. \& Cheng, B. Direct Z-scheme tio2/cds hierarchical photocatalyst for enhanced photocatalytic h2-production activity. Appl. Surf. Sci. 422, 518-527 (2017).

46. Perdew, J. P. et al. Atoms, molecules, solids, and surfaces: Applications of the generalized gradient approximation for exchange and correlation. Phys. Rev. B 46, 6671-6687, DOI: 10.1103/PhysRevB.46.6671 (1992).

47. Perdew, J. P., Burke, K. \& Ernzerhof, M. Generalized Gradient Approximation Made Simple. Phys. Rev. Lett. 78, 1396, DOI: 10.1103/PhysRevLett.78.1396 (1997).

48. Blöchl, P. E. Projector augmented-wave method. Phys. Rev. B 50, 17953-17979, DOI: 10.1103/PhysRevB.50.17953 (1994).

49. Grimme, S. Accurate description of van der waals complexes by density functional theory including empirical corrections. J. computational chemistry 25, 1463-1473 (2004).

50. Heyd, J. Scuseria ge and ernzerhof m. J. Chem. Phys. 2003, 118 (2003).

\section{Acknowledgements (not compulsory)}

K.T. would like to acknowledge VGST (GRD no. 536 CISEE) for financial support.

\section{Author contributions statement}

S.S performed all the experiments and simulations, acquired data, prepared the draft, K.S supervised the experiment. K.T conceptualized, supervised the work and finalized the manuscript. All authors reviewed the manuscript. 